

\title{
The politics of climate policy: strategic options for national governments
}

\author{
Hugh Compston \\ Reader in Politics, Cardiff University \\ Compston@Cardiff.ac.uk
}

\section{Introduction}

One of the distinguishing characteristics of the early $21^{\text {st }}$ century is general agreement that the planet is heating up and that something should be done about this. Governments around the world subscribe to this view, as demonstrated by their explicit acceptance of the key points (summaries for policymakers) of a series of reports by the Intergovernmental Panel on Climate Change (IPCC) and the fact that many have introduced policies designed to limit greenhouse gas emissions. At the same time the Stern Review is merely the most prominent of a wide range of economic analyses to conclude that measures to bring climate change under control can be put in place at an acceptable cost.

Despite nearly two decades of climate policy, however, greenhouse gas emissions are still rising at both global and EU levels. Emissions are continuing to rise in 12 of the $27 \mathrm{EU}$ member states, and a significant proportion of the emission reductions that have occurred in the EU can be attributed more to economic factors, such as the restructuring that followed the end of socialist central planning in central and eastern Europe, than to climate policy ${ }^{1}$.

Why this lack of progress?

The desire is there, the means are available and affordable, so it is difficult to escape the conclusion that the principal obstacles to more effective action are political in nature. Certainly political obstacles can be readily identified. There is the lingering influence of climate sceptics. Governments worry that stringent climate policies will lead companies to redirect investment elsewhere. There is the perception that measures which impose costs on voters will elicit retaliation at the ballot box. And there is the fact that the actions of individual countries, China and the US apart, can make little difference anyway.

What can be done in these circumstances?

One option is to identify better political strategies for activist governments, that is, strategies that will enable them to take more effective action against climate change without incurring significant political damage. We cannot expect democratic governments to implement policies that might endanger their prospects of re-election.

Political scientists have now devoted some attention to this issue, and the international investigation that I lead has identified a range of political strategies that are, or could be, used by national governments. This article summarises our findings so far. ${ }^{2}$ 


\section{Unilateral action}

The strategy favoured by climate scientists is to identify the most technically effective and economically feasible policies and then simply go ahead and introduce them. This is fine when all other relevant political actors agree, or when proposed changes are relatively small, but when politically significant actors oppose the climate policies concerned, which is often the case for policies that would significantly reduce emissions, unilateral action can incur costs such as loss of political support and withdrawal of private investment. This approach is therefore not viable as a general strategy, although it may be worthwhile in some circumstances.

\section{Persuasion}

One obvious response by governments to political opposition is to try to convince opponents that the policies concerned are indeed the right policies. There are a number of tactics that are relevant here.

For policy preferences to change, actors must believe that the information they are given is accurate. For this reason the acquisition and transmission of accurate information is a key strategy. When not used cynically, reports and targets can therefore play an important role in demonstrating to key actors both the nature and scale of the problem, and exactly what needs to be done. In this connection one particularly useful move might be more systematic envisioning of what a low carbon society would look like both to inform the design of policy instruments and to provide more concrete long-term goals for inclusion in messages about climate change and climate policy. The credibility and legitimacy of climate policies could also be improved by developing and disseminating more accurate and transparent methods for measuring and reporting emissions.

It is important to ensure that messages are simple and clear. For this reason dissemination efforts should focus on just a few selected indicators of current and future climate change impacts along with a small number of projected solutions and ensure that reports on these are easy to understand. Metaphors and analogies should be used where these aid understanding. Messages needed to be repeated often enough to become well-known but reformulated periodically so that excessive familiarity does not dull their impact. One particularly important aspect of this strategy is to maximise the visibility and transparency of climate policy initiatives that governments feel could be made popular, such as subsidies for small-scale renewable energy generation.

Every message about climate change should reinforce the fact that the scientific community agrees that global warming is happening and that it is the result of human activity. Messages should stress that the debate is over and point out that the detailed climate models developed by scientists have helped them correctly predict climate change trends and impacts. Messages should also point out that ordinary people are becoming more concerned, as opinion polls indicate that citizens are more likely to be concerned if they are aware that others are too.

Different audiences are (potentially) concerned about different aspects of climate change, so it is vital that messages are tailored accordingly. Stressing the health impacts of climate change is appropriate for general audiences, for example, whereas for business audiences a focus on economic impacts should be preferred. It is also important to stress regional and local impacts and to tailor messages to different geographical audiences so as to 'bring the issue home', as problems that are immediate and proximate to people tend to elicit more concern. In putting across these messages it is important to use spokespeople who have 
credibility in the eyes of particular audiences, such as business leaders for business audiences.

As climate policies affect different groups in different ways in addition to any effects they may have on climate change, it is important to identify and stress any impacts they may have that can be argued to be beneficial to the audience at hand: co-benefits. For business audiences it is vital to stress any business opportunities that climate policies open up, and indeed to select policies partly on this basis. Economists and forward-looking businesspeople may be persuaded that policies designed to encourage investment in new energy technologies, such as photovoltaic cells, will in due course enable the country to benefit from a first mover advantage. For security-conscious audiences the same policies can be presented as measures that improve energy security by reducing the need for oil and/or gas imports. And it can be pointed out that measures to encourage switches in travel behaviour from private cars to public transport can ease traffic congestion as well as reduce carbon dioxide emissions.

There is also reason to believe that it is important to appeal to a wide range of rationalities. The idea here is that market instruments appeal to just one type of human rationality, namely that of an economic actor who responds only in a self-interested way to price signals, whereas in fact there is considerable evidence that individuals and organisations use other rationalities as well. Egalitarians, for example, want greater equity between humans and between humanity and nature, while hierarchicalists want better governance and planning to ensure that the natural world and its resources are better managed. This suggests that messages should be formulated to appeal to each of these different rationalities and that a combination of policy instruments needs to be put in place in order to secure wide support.

It is important to be positive. Messages about climate change often engender feelings of demoralisation and helplessness due to the mismatches between the scale and causes of the problem and the capabilities of individuals and local communities to act effectively. It is therefore essential to blend negative messages, which are needed to raise concern, with positive messages that explain how individuals and communities can make a difference. One such message should be that we do not have to wait for some future technology to save us but can begin to implement existing solutions today. Technologies to increase energy efficiency, for example, can often be quickly deployed at relatively low cost. Conversely it is vital to stress the cost of doing nothing by means such as pointing to the costs that have already been incurred as a result of floods, hurricanes and the like, as well as highlighting economic analyses that indicate that these costs will grow in the future if nothing is done.

As moral and ethical concerns can inspire citizens to accept policies that require personal sacrifices because they believe that important ethical issues are at stake, it is worth stressing the disproportionate effects that climate change is likely to have on poorer sections of society (nationally and globally) and on people who have not benefited from the ready availability of cheap energy the generation of which has been responsible for a large proportion of the accumulation of $\mathrm{CO} 2$ in the atmosphere. This line of thought also suggests that climate policies which are seen to distribute costs equitably may encounter less political opposition than policies which are perceived as being unfair.

Another important strategy is to use insights from theories of communications such as frame analysis and discourse theory to construct new and more potent storylines. In this connection it is instructive to look at the so-called securitisation of climate change. Energy security has already been mentioned as a co-benefit of certain types of climate policy, but framing climate change as a threat to security in a broader sense, on the basis that it will inevitably exacerbate political tensions, directs attention to concepts such as threat, danger, 
enemy, attack and defend and prioritises the concerns, strategies and norms of national defence and intelligence communities. The point is that this type of framing should attract the interest and support of new and powerful political actors. The security frame also enables the use of powerful metaphors, such as the Manhattan Project, to describe the efforts required to bring climate change under control. And constructing climate change as a threat to the stability of the nation-state can be construed as a 'move that takes politics beyond the established rules of the game and frames the issue as either a special kind of politics or above politics ... something [that] overflows the normal political logic of weighing issues against each other'. ${ }^{3}$ Perhaps even more promising, at least in the American context, is the recent effort to liken the required action on climate change to the Apollo programme of the 1960s that put a man on the moon, as this reframes the issue into one that foregrounds the economic and social opportunities inherent in the construction of a green economy. This emphasis on industrial transformation and economic opportunity is something that even climate sceptics can support. While these particular strategies are more applicable to the US than elsewhere, they demonstrate the potential in other countries too for devising frames and storylines that are better attuned to national specificities and contemporary concerns than those currently in circulation. One recent example of this was the attempt to turn the economic crisis of 2008 to advantage by portraying spending on efforts to control climate change as a Green New Deal. More such innovations will be needed in the years ahead.

Finally, delivering carefully crafted messages is not the only means by which activist governments can try to alter the policy preferences of others. Another possibility is to create conditions which lead other actors to change their preferences as a consequence of learning for themselves. Perhaps the most prominent contemporary example of such a strategy is the transitions management approach. This is based on the idea that new socio-technical regimes emerge through successful application and learning in 'protected spaces' in which new technologies and social practices are not exposed to the full selective pressures operating in the incumbent regime. Applying this approach to climate policy would involve beginning by setting a low carbon goal such as a national or sector emissions reduction target. A series of multi-participant 'transition arenas' would then be convened to identify those regimes where emissions are most significant or the potential for change is greatest. Each transition arena would then go through an iterative process of (1) understanding the carbon reduction challenge for the existing regime and identifying 'transition goals' such as making electricity supply more sustainable; (2) developing a consensus about alternatives and a basket of 'visions' that are compatible with the transition goals; (3) identifying 'pathways' towards those visions, such as expansion of particular types of renewable energy; (4) instigating niche experiments that contribute to the realization of these pathways; and (5) establishing processes for social learning and reflexivity across all of these activities. The idea is that over time this would lead to a gradual transfer of institutional support away from the existing regime towards a low carbon regime and the public policies that realizing this would require ${ }^{4}$.

\section{Damage limitation}

But suppose persuasion doesn't work. It is not easy to change people's preferences.

One possible response is for governments to go ahead anyway but employ tactics designed to enable them to avoid institutional veto points and minimise political damage. Where opponents are in a position to block climate policies by means such as denying official approval, mounting legal challenges or refusing to cooperate with implementation, an obvious response is to choose policy instruments that do not require legislation, are secure from legal challenge and do not require the cooperation of other actors for implementation. Introducing unpopular policies early in a government's term of office may allow time for 
opposition to subside and for the benefits of controversial policies to become apparent before the next election arrives. Targeting economic sectors that are able to pass on at least a proportion of their extra costs to consumers, such as the power generation sector, should help to minimise both business opposition and the chances that voters will blame the government for these higher costs, although this strategy will be undermined to the extent that media outlets publicise this connection. A further tactic is to adopt policies that target losses on small sections of society, in particular those groups that are least able to exercise threats to withdraw investment from the country or inflict political damage via the ballot box. Compensating powerful actors for the imposition of more progressive climate policies, even when their explicit agreement to these cannot be obtained, may nevertheless weaken their resistance to these policies and therefore reduce the political costs that these actors inflict on the governments that introduce them. The opposition of business to the imposition of a carbon tax, for example, may be blunted if the revenue from such a tax is used to reduce employers' social contributions. And moving to have relevant decisions taken at other levels of governance, in particular the European level, may enable national governments to deflect the blame for unpopular climate policies.

Finally, public actors can take advantage of events that temporarily reduce opposition to strong action on climate change. This is an especially important point. If climate change is really under way we can expect increasingly frequent and serious weather-related natural disasters. To the extent that these are linked by the media to climate change, and they will be, we can expect temporary spikes in public demand for strong climate policies which reduce the political costs that such policies would otherwise incur. For this reason we can expect windows of opportunity to open on a regular basis for governments that keep fully-prepared policy options ready to go.

\section{Exchange policy concessions for acquiescence}

But these strategies may not work either, or may be considered too risky to try.

What governments faced with powerful opponents normally do is to offer policy concessions in exchange for their acquiescence. The strategic choices to be made by governments engaging in political exchange include deciding which actors need to acquiesce if unacceptable political damage is to be avoided, and deciding exactly what policy concessions they are prepared to make in order to secure that agreement. Different strategic choices can lead to different policy decisions by leading public actors to make different types of policy concessions. Different alliances, for example, may permit the achievement of different policy goals.

There are also some more specific tactics that can be employed. One of the most obvious is to offer access to policy making, such as seats on advisory committees, as a substitute for policy concessions. Another is to put together package deals whereby opponents of particular climate policies are offered concessions in other policy areas, such as tax cuts, instead of amendments to the climate policies in question. A third is to negotiate agreements whereby industry groups agree to reduce their emissions in exchange for the nonimposition or delay of legal requirements. Arguably one of the most effective tactics is to negotiate cross-party agreements on climate policy, as such agreements both reduce the possibility that a change of government would lead to the relevant measures being repealed and weaken the incentive for opponents of the policies concerned to shift their support to other parties. 


\section{Alter the terms of exchange}

The problem with exchanging policy concessions for acquiescence, of course, is that it weakens climate policies. But if unilateral action leads to political damage, and persuasion is often ineffective, what can governments and actors within governments do?

At least part of the answer is for governments to take steps to alter the terms of exchange between themselves and other political actors. To be more precise, governments need to reduce their dependence on other actors and increase the dependence of other actors on them. To the extent that this is achieved, the stronger bargaining position for governments that results should enable them to obtain the acquiescence of other actors to stronger climate policies at a lower cost in terms of policy concessions than would otherwise be the case. What this means is that altering the terms of exchange should enable governments to introduce stronger climate policies without eliciting retaliation and political damage.

One way of shifting the terms of exchange would be to strengthen the legal powers of government in certain ways. For a start, this can enable them to introduce climate policies that they would not previously have been authorised to introduce. In addition, extending the remit of climate ministers to cover energy, as was done recently in Britain, may remove at least one significant potential veto point within officialdom and cabinet as well as extending both the range of possible policy amendments that climate ministers can offer to other actors in exchange for their acceptance of climate policies and the range of policy decisions on which their formal approval is necessary for policies desired by other actors. Centralizing planning powers enables national governments to override objections from local authorities and others to energy infrastructure projects, such as nuclear power stations, as well as extending their ability to approve or block infrastructure projects desired by others. Veto points in climate policy decision making may be removed by altering formal decision making procedures by means such as reducing the power of upper chambers of legislatures and passing framework legislation that enables a greater range of climate policies to be introduced by regulation rather than legislation. Governments could bypass limitations on their own legal authority, and thereby in effect extend it, by moving to have relevant decisions taken at levels of governance at which public actors have the relevant powers, such as the European level. Vulnerability to legal challenge could be reduced by strengthening or clarifying national law and/or by transferring relevant decisions to jurisdictions in which the policies concerned have a sound legal basis, again such as the European level. And governments could increase the significance of their control of access to policy making by removing any legal rights of access for stakeholders, such as seats on committees, so that instead access can be granted or denied at the discretion of the relevant public actor and thereby used as a bargaining counter.

In some circumstances governments can be prevented from introducing new climate policies because firms withhold the information they need to assess whether such policies would work and how exactly they should be structured. This dependence on others for information could be reduced by governments taking steps to obtain information from alternative sources, such as foreign governments or foreign companies in the same industry, and/or by building up their own in-house capacity by means such as by setting up or strengthening dedicated research units.

In a number of areas governments are dependent on private firms to implement climate policies. If the British government is to succeed in decarbonising Britain's energy supply, for example, it needs private companies to build and operate the required types of power stations. Governments that enhance their ability to reward or punish these companies are obviously in a better position to secure this cooperation. Where companies are legally required to 
implement policies such as energy efficiency standards, the incentive to cooperate can be strengthened by increasing penalties for non-compliance. In other cases strengthening financial incentives for cooperation is more appropriate. Cooperation with implementation can also be improved by introducing supplementary policies. Energy company investment in carbon capture and storage, for example, could be made less risky, and therefore more likely, by finalising a long-term stable regulatory framework.

Where these tactics fail, governments could move to secure alternative means of implementing climate policies. New firms, such as foreign multinational companies, might be attracted to undertake tasks that others will not touch. Another option would be to strengthen the capacity of the state itself to implement public policy by means such as forming state agencies to build power stations equipped with carbon capture and storage, or by buying or nationalizing one or more major energy firms.

In addition to efforts to increase political support for climate policies by persuading actors and voters to alter their policy preferences, there are at least two ways in which governments and actors within governments can try to strengthen political support for more radical action. The first is to install more climate policy-friendly politicians and officials in key positions in order to reduce the likelihood that incumbents of these positions will withhold approval from climate policies. The second is to respond to opposition to key climate policies among existing supporters by cultivating other sections of the electorate. Whether this can in fact be done is unclear, but the possibility that it might work under certain conditions cannot be ruled out altogether.

One of the most potent political weapons for private firms today is their ability to withdraw or withhold investment if climate policies are not to their liking, for example because they raise production costs relative to those in other countries. However there are at least three ways in which governments can move to improve their bargaining position in such situations. First, they can try to compensate for any investment lost by attracting new foreign investment. Second, they can strike international agreements that remove the possibility that firms can get a better deal elsewhere and thereby reduce or remove the incentive for businesses to relocate investment. Global agreement on a carbon tax, for example, would remove the possibility of moving to a jurisdiction without a carbon tax. Third, governments could impose stricter controls on international capital transactions in order to make it harder for firms to shift investment to other countries. Such a move might appear unlikely at a time in which free trade and international capital mobility are very much favoured by economic and political elites, but it is worth noting that stricter controls could be imposed very swiftly.

The final point relates to the fact that policy making can be influenced by patronage and cash as well as by more legitimate policy and political considerations. For this reason one useful tactic for governments would be to add to their own powers of patronage, for example by means of creating more posts/honours for distribution to private actors, while restricting the use of patronage by others by means such as tightening legal restrictions on the use of inducements, such as well-paid seats on company boards, to persuade politicians and officials to weaken climate policies. Similarly, governments could reduce the ability of other actors to secure policy concessions from elected or appointed officials in exchange for bribes, campaign contributions or other financial inducements by tightening legal restrictions on the provision and acceptance of such inducements and by stepping up law enforcement efforts. The ability of governments themselves to use cash in forms such as subsidies to buy off opposition to climate policies, or to secure their implementation, is obviously enhanced to the extent that relevant budgets are increased. 


\section{Other strategies}

It is clear that there are numerous political strategies and tactics available to governments that want to take stronger action on climate change. Before we bring this account to an end, however, it is worth looking at three further strategies that don't fit neatly into any of the general categories used so far.

The first is to delegate at least some decision making on climate policy to non-partisan agencies in order to try to depoliticise climate policy, as this should reduce the possibility that a change of government would lead to the relevant measures being repealed and thereby weaken the incentive for opponents of the policies concerned to shift their support to opposition parties.

Second, governments could alter the organisation of interactions with political actors outside government by reforming advisory committees, consultative arrangements and lobbying rules. One possibility would be to make it more difficult for business to obtain policy concessions behind closed doors by providing seats for independent climate experts on all official climate change-related committees on which industry is represented. In some circumstances giving new actors access to the policy making process may make them more likely to accept proposed policy changes, while in others their exclusion may make action more likely by removing any presumption that their agreement is a prerequisite.

Finally, governments could take greater advantage of the logic of policy spillover whereby certain policies, once implemented, exert pressure on governments to continue on the same policy path. In relation to climate policy this means, first of all, policies that are relatively easy to transfer to other countries, such as measures to encourage renewable technologies that can be easily adopted by developing countries. Second, it means policies that are particularly difficult to reverse, such as long-term contracts that commit future governments to major investment in the restructuring of energy supply. Finally, there are climate policies that create functional or political pressure for their own strengthening or for the introduction of related measures, such as policies that lead to increased investment and employment in the renewables sector.

\section{And the future}

Climate change, if the IPCC is correct, will cause increasingly severe damage as time goes on unless greenhouse gas emissions are brought under control. This article has identified a wide range of possible strategies for governments that want to take more effective action against climate change without incurring significant political damage. Not all of these are mutually compatible, or appropriate for every government, but together they constitute a menu of strategic options from which governments can choose. I would like to conclude by listing some of the most promising of these.

First, there are techniques of persuasion:

- Introducing new frames and storylines;

- Facilitating learning by means such as transitions management.

Second, there are damage limitation tactics:

- Assembling package deals whereby opponents accept climate policies in return for compensation in other policy areas;

- Negotiating cross-party agreements. 
Certain tactics in political exchanges with other actors can be particularly effective:

- Distributing costs equitably;

- Targeting costs on economic sectors that can pass them on;

- Targeting costs on groups least able to retaliate by inflicting political damage;

- Compensating powerful actors to weaken their opposition.

Fourth, governments may move to alter the terms of exchange by:

-Extending the range of policy areas over which climate ministers have legal authority;

- Centralising planning powers;

- Installing more climate-friendly politicians and officials in key positions;

- Altering decision making procedures to remove veto points;

- Building up in-house capacity to implement climate policies;

- Buying or nationalising key firms;

- Cultivating new sections of the electorate to replace those antagonised by radical climate policies.

And there are three important strategies that don't fit into any of these categories:

- Delegating decision making to non-partisan agencies;

- Providing seats for independent climate experts on all climate policy-relevant committees on which industry is represented;

-Placing greater emphasis on spillover policies.

\footnotetext{
1 Pieter Tans, 'Recent monthly mean $\mathrm{CO}_{2}$ at Mauna Loa (2005-2009)', http://www.esrl.noaa.gov/gmd/ccgg/trends/ [27 April 2009]; European Environment Agency, Greenhouse Gas Emission Trends and Projections in Europe 2008: Tracking Progress Towards Kyoto Targets. EEA Report No. 5/2008, http://www.eea.europa.eu/publications/eea_report_2008_5 [18 June 2009], pp. 17-19.

${ }^{2}$ Hugh Compston and Ian Bailey, eds., Turning Down the Heat: The Politics of Climate Policy in Affluent Democracies, Basingstoke, Palgrave Macmillan, 2008; Hugh Compston, ed., Climate Policy and Political Strategy, Special Book Issue of Environmental Politics, 18(5), September 2009.

${ }^{3}$ B. Buzan, O. Waever and J. de Wilde, Security: A New Framework for Analysis, Boulder and London: Lynne Rienner, 1998, pp. 21-23.

${ }^{4}$ Ivan Scrase and Adrian Smith, 'The (non-)politics of managing low carbon socio-technical transitions', in Compston, Climate Policy and Political Strategy.
} 